\title{
Genetic changes in pigeon paramyxovirus type-1 induced by serial passages in chickens and microscopic lesions caused by the virus in various avian hosts
}

\author{
Monika Olszewska-Tomczyk ${ }^{1}$, Izabella Dolka ${ }^{2}$, \\ Edyta Świętoń ${ }^{1}$, Krzysztof Śmietanka $^{1}$ \\ ${ }^{1}$ Department of Poultry Diseases, National Veterinary Research Institute, 24-100 Pulawy, Poland \\ ${ }^{2}$ Department of Pathology and Veterinary Diagnostics, Faculty of Veterinary Medicine, \\ Warsaw University of Life Sciences, 02-776 Warsaw, Poland \\ monika.olszewska@piwet.pulawy.pl
}

Received: June 6, 2018

Accepted: October 25, 2018

\begin{abstract}
Introduction: Genotype VI of avian avulavirus 1 (AAvV-1) has pigeons and doves as its reservoir and is often termed pigeon paramyxovirus type-1 (PPMV-1). The pathogenesis of PPMV-1 infections in poultry is largely obscure. It is known that PPMV-1 requires a series of passages in chickens before it becomes adapted to gallinaceous poultry. Material and Methods: Changes in the genome of PPMV-1 were analysed after serial passages in specific pathogen free (SPF) chickens, using highthroughput sequencing. Additionally, histopathological lesions induced by PPMV-1 in experimentally inoculated pigeons, chickens, and turkeys were evaluated. Results: Following six passages of PPMV-1 in chickens, 10 nonsynonymous substitutions were found including one (in the NP protein) which dominated the genetic pool of viral quasispecies. Histopathological changes induced by the post-passage PPMV-1 strain were more prominent than changes wrought by the pre-passaged PPMV-1 strain and the lesions were most intense in pigeons followed by chickens and turkeys. Conclusion: PPMV-1 is highly adapted to pigeons and passaging through chickens results in the acquisition of novel amino acids in the polymerase complex, which may alter the pathogenic potential of the virus.
\end{abstract}

Keywords: pigeons, poultry, pigeon paramyxovirus type-1, histopathological lesions, high-throughput sequencing.

\section{Introduction}

Avian avulavirus $1(\mathrm{AAvV}-1)$ is a species in the Paramyxoviridae family that encompasses different strains of avian paramyxoviruses type 1 (APMV-1) and affects wild and domestic avian hosts worldwide (1, 4, 9). The virus genome consists of a single molecule of single-stranded negative-sense RNA. Six structural proteins are encoded in the genome in the following order $\left(3^{\prime}-5^{\prime}\right)$ : nucleocapsid protein (NP), phosphoprotein $(\mathrm{P})$, matrix protein $(\mathrm{M})$, fusion protein (F), haemagglutinin-neuraminidase (HN), and polymerase (L). Additionally, nonstructural proteins V and $\mathrm{W}$ are generated via the RNA editing of the $\mathrm{P}$ gene (29). Similarly to other RNA viruses, AAvV-1 shows high variability, leading to generation of a diverse population of virus variants (quasispecies) which is an important factor affecting virus pathogenicity and adaptation properties $(5,23)$

Infections with AAvV-1 have a broad range of clinical manifestations, from asymptomatic through mild (with little or no mortality) to systemic (with moderate to high mortality) (1). The latter form, caused by virulent strains of $\mathrm{AAvV}-1$, has been termed Newcastle disease (ND). The most important virulence marker is located in the F protein which is responsible for the fusion of the viral envelope with the endosomal membrane. $\mathrm{F}$ protein is produced as an inactive form F0 which needs cleavage into two subunits. The protein cleavage site of avirulent strains is monobasic and can be cleaved by trypsin-like proteases restricted to the respiratory and gastrointestinal tracts. In contrast, virulent strains have multiple basic amino acids at this motif which makes it susceptible to cleavage by 
ubiquitous host proteases resulting in systemic infections (12). However, the presence of a multibasic F cleavage site is not a definitive pathotype determinant and other genes also contribute to the virulence (26).

There is a great genetic diversity among circulating AAvV-1 strains and based on the genetic characterisation of the fusion gene $(F)$, two major genetic groups have been distinguished: class I and class II (9). Class I AAvV-1 strains are genetically homogenous and constitute a single genotype, mostly comprising strains of low virulence. The class II group is genetically very diverse and has been divided into 18 genotypes designated I to XVIII. The vast majority of class II AAvV-1 strains isolated from wild, feral and domestic pigeons have been classified to genotype VI and are frequently referred to as "pigeon paramyxovirus type 1" (PPMV-1). Since the late 1970 s, there has been an ongoing panzootic in pigeons caused by PPMV-1 with occasional spillovers to poultry (9). In Europe, the disease in pigeons is widespread and has reached the status of endemicity (2). However, with the exception of rare epidemics of considerable magnitude in fowl (3), the incidence of reported PPMV-1 infections in poultry is relatively very low, considering the frequency of potential contacts between pigeons and poultry (2).

The control of Newcastle disease in poultry does not take the genotype of $\mathrm{AAvV}-1$ into account, but only the virulence of the strain that has caused infection (2, 8). Thus, the identification of virulent PPMV-1 in avian species that fall under the definition of "poultry" results in the notification of a Newcastle disease outbreak. Due to high adaptation to pigeons, natural infections with virulent PPMV-1 in fowl are often subclinical because the virulence criteria rely on the results of intracerebral inoculation of 1-day-old chicks, which is not the natural route of infection, or the assessment of molecular markers of virulence that do not always translate into pathogenicity in vivo $(8,24)$. In the current study, a detailed analysis of the genetic changes that occurred in the PPMV-1 as a result of serial passages in chickens were performed and pathological lesions induced by PPMV-1 in selected tissues of experimentally inoculated pigeons, chickens, and turkeys were assessed.

\section{Material and Methods}

Experimental design. The experimental setup was described previously (21). Briefly, the isolate PPMV-1/pigeon/Poland/332/05 was passaged six times in 3-week-old SPF chickens. First, three chickens were inoculated in the breast muscle with a dose of $10^{7.3}$ EID $_{50}$ of PPMV-1/pigeon/Poland/332/05 propagated in SPF embryonated eggs $(332 / 05 / 0)$. On day 3 post infection (dpi) the birds were euthanised and spleens were collected and homogenised in PBS to obtain $20 \% \mathrm{w} / \mathrm{v}$ suspension. The homogenate was then centrifuged (15 min, $3,000 \times g)$ and the supernatant was used for inoculation of another group of SPF chickens. A total of six passages were performed in this way. Spleens of chickens from the $6^{\text {th }}$ passage were prepared as described above and the obtained virus stock was designated $332 / 05 / 6$. The viruses from the initial virus stock $(332 / 05 / 0)$ and the post-passage virus (332/05/6) were used to inoculate ten 8 -month-old pigeons, 3-week-old chickens, and 3-4-week-old turkeys via intraocular and intranasal routes with $10^{6} \mathrm{EID}_{50}$ of each virus/bird. On the $4^{\text {th }}, 7^{\text {th }}, 10^{\text {th }}$, and $14^{\text {th }} \mathrm{dpi}$ in the case of pigeons, and on the $4^{\text {th }}, 7^{\text {th }}$, and $10^{\text {th }}$ dpi in the case of chickens and turkeys, two birds were euthanised and samples of the liver, kidney, duodenum, lung, pancreas, and brain were aseptically collected for histopathological examination.

RT-PCR and Sanger sequencing. The viral RNA from allantoic fluid of 332/05/0 and spleen homogenate of 332/05/6 was extracted with a QIAamp Viral Mini Kit (Qiagen, Germany), according to the manufacturer's protocol. The primers used in the RTPCR were designed on the basis of sequences collected in the GenBank database (www.ncbi.nlm.nih.gov) and were all synthesised by Genomed (Poland). Sequences are presented in Table 1. The OneStep RT-PCR kit (Qiagen, Germany) was used according to the manufacturer's instructions with the final primer concentration of $1 \mu \mathrm{M}$. With primer annealing temperature known to be around $55^{\circ} \mathrm{C}$, the RT-PCRs were performed in the stages as follow: reverse transcription at $50^{\circ} \mathrm{C}$ for $30 \mathrm{~min}$, denaturation at $95^{\circ} \mathrm{C}$ for $15 \mathrm{~min}$, and 40 cycles of $95^{\circ} \mathrm{C}$ for $15 \mathrm{~s}, 55^{\circ} \mathrm{C}$ for $30 \mathrm{~s}$, and $72^{\circ} \mathrm{C}$ for $1 \mathrm{~min}$. The reaction was staged in a Veriti thermal cycler (Applied Biosystems, USA). The PCR products were purified with an ExoSAP-IT kit (Affymetrix, USA) and were sequenced using a BigDye Terminator v3.1 Cycle Sequencing kit (Applied Biosystems, USA) in a 3500 genetic analyser (Applied Biosystems). Chromatograms were assembled with BioEdit software (version 7.2.5., Tom Hall of Ibis Therapeutics, USA) to obtain consensus sequences of $332 / 05 / 0$ and 332/05/6. Molecular analysis comparing sequences of both strains was performed in MEGA6 software (32) and included all viral genes.

Deep sequencing and bioinformatic analysis. For deep sequencing, the RNAs from both virus stocks were extracted with a NucleoSpin NA Plus kit (Macherey-Nagel, Germany), including a step of genomic DNA removal. Separate templates were prepared for viruses 332/05/0 and 332/05/6. Prepared libraries were sequenced with SBS (sequencing by synthesis) conducted in MiSeq in mode PE250 (Illumina, USA). Library preparation and sequencing was performed by Genomed. The quality of raw reads was examined in FastQC software (www.bioinformatics.babraham.ac.uk/projects/fastqc/). The reads were trimmed in Trimmomatic (The Usadel Lab, Germany) to remove low quality data and adapter sequences (7) and then were assembled in the 
Burrows-Wheeler alignment tool (BWA) (http://biobwa.sourceforge.net) (20) with the consensus sequence of $332 / 05 / 0$ as a reference. BAM files were processed in Samtools (www.htslib.org) to obtain mpileup files used as an input for variant calling in VarScan (http://varscan.sourceforge.net) (18). To minimise the probability of false positive calls resulting from sequencing errors, only variants with a frequency of $>1 \%$ in positions with a coverage of $\geq 500 \times$ were considered. All variants were inspected visually in the alignment in Tablet software (https://ics.hutton.ac.uk) (25).

Table 1. Sequences of primers used for amplification and Sanger sequencing

\begin{tabular}{|c|c|c|c|}
\hline Primer & Sequence 5'-3' & Location in the genome & Product length $(\mathrm{bp})$ \\
\hline $332-1 \mathrm{~F}$ & ACCAAACAGAGAATCKGTGA & $1-20$ & \multirow{2}{*}{792} \\
\hline $332-1 \mathrm{R}$ & GAATGTCTGATTGTGAGTTGAA & $771-792$ & \\
\hline $332-2 \mathrm{~F}$ & AGACAGCAGATGAGTCAGA & $672-690$ & \multirow{2}{*}{762} \\
\hline $332-2 \mathrm{R}$ & GTTGCCCTTGCGACCTGC & $1,416-1,433$ & \\
\hline $332-3 \mathrm{~F}$ & TGGACATTCCCACTCAACA & $1,338-1,356$ & \multirow{2}{*}{659} \\
\hline $332-3 R$ & CCGACAGTCTCTGCTGATCTG & $1,976-1,996$ & \\
\hline $332-4 \mathrm{~F}$ & TTACCGATGCTGAGATAGAGG & $1,903-1,923$ & \multirow{2}{*}{838} \\
\hline $332-4 \mathrm{R}$ & TCCAGAATTTTCATCATGCCTA & $2,719-2,740$ & \\
\hline $332-5 \mathrm{~F}$ & ATGATGTCTATGATGGAGGCG & $2,571-2,591$ & \multirow{2}{*}{861} \\
\hline $332-5 R$ & GACGCTGGATCCTGTATTG & $3,413-3,431$ & \\
\hline $332-6 \mathrm{~F}$ & ATCAATCTAACAGCATTAGAGA & $3,228-3,249$ & \multirow{2}{*}{694} \\
\hline $332-6 \mathrm{R}$ & GTGACATTGAGCGCGAGA & $3,904-3,921$ & \\
\hline $332-7 \mathrm{~F}$ & GTGAAGGCACCTGAAAAGA & $3,764-3,782$ & \multirow{2}{*}{718} \\
\hline $332-7 \mathrm{R}$ & GGTAAACTAACTATAAGCAATC & $4,460-4,481$ & \\
\hline $332-8 \mathrm{~F}$ & ATAGAGAAGAGGCACACCA & $4,343-4,361$ & \multirow{2}{*}{739} \\
\hline $332-8 \mathrm{R}$ & CCACTGCTAGCTGCGATAATC & $5,061-5,081$ & \\
\hline $332-9 \mathrm{~F}$ & GCCATTATAGGCAGTGTAG & $4,907-4,925$ & \multirow{2}{*}{740} \\
\hline $332-9 \mathrm{R}$ & TTGCCGCTCAGACAAGAA & $5,629-5,646$ & \\
\hline $332-10 \mathrm{~F}$ & GGCTCTGTGATAGAAGAAC & $5,528-5,546$ & \multirow{2}{*}{653} \\
\hline $332-10 \mathrm{R}$ & AGGGTGTTGTTCCCAAGCCACA & $6,159-6,180$ & \\
\hline $332-11 \mathrm{~F}$ & TGTCAAACTAACCAGCACATC & $6,025-6,045$ & \multirow{2}{*}{912} \\
\hline $332-11 \mathrm{R}$ & AGTGCAGCCTGATCCTGTA & $6,918-6,936$ & \\
\hline $332-12 \mathrm{~F}$ & CAATAACATCTCTCTCTCATC & $6,734-6,754$ & \multirow{2}{*}{836} \\
\hline $332-12 R$ & CTCACCCAAAGATGTTGACAC & $7,549-7,569$ & \\
\hline $332-13 F$ & GTTGAAACCCAATTCGCCTA & $7,374-7,393$ & \multirow{2}{*}{796} \\
\hline $332-13 R$ & ATCCTACATTCGACTCAAC & $8,151-8,169$ & \\
\hline $332-14 \mathrm{~F}$ & AGCATACACGACATCGACA & $7,989-8,007$ & \multirow{2}{*}{771} \\
\hline $332-14 \mathrm{R}$ & CGTACCTCGTGTTGTGAATTTG & $8,738-8,759$ & \\
\hline $332-15 \mathrm{~F}$ & CTGCCACTCCTGATATTGA & $8,568-8,586$ & \multirow{2}{*}{829} \\
\hline $332-15 R$ & GCGTGAGTTACTGATTCCGC & $9,377-9,396$ & \\
\hline $332-16 \mathrm{~F}$ & GGCAATCAAGTCTATGATG & $9,221-9,239$ & \multirow{2}{*}{762} \\
\hline $332-16 \mathrm{R}$ & TCTYAGGTACTCAAGGGTTG & 9,963-9,982 & \\
\hline $332-17 \mathrm{~F}$ & AAGCAGGTGAAGGAGGCAAC & $9,869-9,888$ & \multirow{2}{*}{816} \\
\hline $332-17 \mathrm{R}$ & GGAGTCATCTGATCTTACTTC & $10,664-10,684$ & \\
\hline $332-18 \mathrm{~F}$ & TGCCAGAAGCTATGGACAATG & $10,547-10,567$ & \multirow{2}{*}{799} \\
\hline $332-18 \mathrm{R}$ & GGCTTGCAACAGTCTCAA & $11,328-11,345$ & \\
\hline $332-19 \mathrm{~F}$ & CAGAGGTCAAGCGATTAG & $11,205-11,222$ & \multirow{2}{*}{864} \\
\hline $332-19 \mathrm{R}$ & CCCAGATTAACACGGACGATG & $12,048-12,068$ & \\
\hline $332-20 \mathrm{~F}$ & GAGCTGACTGACGATACCA & $11,915-11,933$ & \multirow{2}{*}{840} \\
\hline $332-20 \mathrm{R}$ & CTGGGCTTCACTAATCCAA & $12,736-12,754$ & \\
\hline $332-21 \mathrm{~F}$ & AAGACTATTTACTGAAGAAGGAA & $12,280-12,302$ & \multirow{2}{*}{720} \\
\hline $332-21 R$ & TCTGCAAGCTGGTGTGAC & $12,982-12,999$ & \\
\hline $332-22 \mathrm{~F}$ & AGTGAGAGGTCTCAACAACA & $12,835-12,854$ & \multirow{2}{*}{801} \\
\hline $332-22 \mathrm{R}$ & GCAGTCCCTATTCCTCTGAA & $13,616-13,635$ & \\
\hline $332-23 \mathrm{~F}$ & AACCTGCATCATTCATACAAGAA & $13,488-13,510$ & 832 \\
\hline $332-23 R$ & TTTGCCATCCTCACTACT & $14,302-14,319$ & 832 \\
\hline $332-24 \mathrm{~F}$ & GTGGAGTAGTGATCATCAAAG & $14,118-14,138$ & \\
\hline $332-24 \mathrm{R}$ & GGAGTAAACAAGAACACTGTG & $14,632-14,652$ & 535 \\
\hline $332-25 \mathrm{~F}$ & CAGAGAGTTTRGTGRGCACA & $14,514-14,533$ & 676 \\
\hline $332-25 \mathrm{R}$ & AAACAAAGATTTGGTGAATGACAA & $15,166-15,189$ & $0 / 0$ \\
\hline
\end{tabular}


Histopathology. Tissue samples were fixed in $10 \%$ buffered formalin, processed, and paraffin embedded. Paraffin blocks were cut into $6 \mu \mathrm{m}$ sections, and then stained with haematoxylin and eosin (HE). Each tissue sample was evaluated for the presence of elementary histopathological lesions, e.g., cellular infiltration (mononuclear or mixed), necrosis, degeneration, congestion, haemorrhages, and other lesions specific for the organ/tissue (e.g. hepatic macrophages hyperplasia, gliosis, or BALT hyperplasia) in 10 randomly selected fields for each case at magnification $10 \times$ and $40 \times$. Grading of lesions was carried out on a descriptive scale as follows: none, scant, mild, moderate, and severe.

\section{Results}

Molecular analysis of non-passaged and passaged isolate. Comparison of consensus sequences of $332 / 05 / 0$ and $332 / 05 / 6$ viruses revealed one nonsynonymous mutation located in position 1,550 in the NP gene. This change resulted in substitution of histidine with asparagine in position 477 of the NP protein. However, deep sequencing revealed the presence of minority variants in both $332 / 05 / 0$ and $332 / 05 / 6$ virus populations. Five low frequency variants were identified in $332 / 05 / 0$, all located in the L gene.

Table 2. Location and frequency of variants in the virus population of post-passage 332/05 (332/05/06) in reference to the consensus sequence of non-passaged virus stock (332/05/0)

\begin{tabular}{|c|c|c|c|c|c|}
\hline $\begin{array}{l}\text { Nucleotide } \\
\text { position }\end{array}$ & $\begin{array}{l}\text { Nucleotide in } \\
\text { consensus sequence } \\
\text { of } 332 / 05 / 0\end{array}$ & $\begin{array}{l}\text { Nucleotide } \\
\text { variant in } \\
332 / 05 / 6 \\
\end{array}$ & Variant frequency (\%) & $\begin{array}{l}\text { Amino acid change } \\
332 / 05 / 0 \rightarrow 332 / 05 / 6\end{array}$ & Protein \\
\hline 1,503 & $\mathrm{C}$ & $\mathrm{T}$ & 2.28 & $\mathrm{~A} 461 \mathrm{~V}$ & \multirow{5}{*}{ NP } \\
\hline 1,550 & $\mathrm{C}$ & $\mathrm{A}$ & 80.75 & $\mathrm{H} 477 \mathrm{~N}$ & \\
\hline 1,576 & $\mathrm{C}$ & $\mathrm{A}$ & 5.36 & none & \\
\hline 1,829 & $\mathrm{~T}$ & $\mathrm{C}$ & 1.34 & non-coding & \\
\hline 1,856 & $\mathrm{C}$ & $\mathrm{T}$ & 5.81 & non-coding & \\
\hline 2,072 & $\mathrm{C}$ & $\mathrm{T}$ & 2.6 & none & \multirow{6}{*}{$P$} \\
\hline 2,154 & $\mathrm{C}$ & $\mathrm{T}$ & 17.68 & P88S & \\
\hline 2,407 & $\mathrm{C}$ & $\mathrm{T}$ & 20.97 & P172L & \\
\hline 2,718 & $\mathrm{~T}$ & $\mathrm{C}$ & 4.77 & none & \\
\hline 2,846 & A & G & 6.4 & none & \\
\hline 3,014 & $\mathrm{~T}$ & $\mathrm{~A}$ & 1.26 & S374R & \\
\hline 3,337 & $\mathrm{C}$ & $\mathrm{T}$ & 13.64 & none & \multirow{3}{*}{ M } \\
\hline 3,927 & A & G & 1.39 & $\mathrm{D} 211 \mathrm{G}$ & \\
\hline 4,141 & $\mathrm{G}$ & $\mathrm{T}$ & 1.28 & none & \\
\hline 4,494 & $\mathrm{~T}$ & $\mathrm{~A}$ & 2.23 & non-coding & \\
\hline 5,755 & $\mathrm{~A}$ & $\mathrm{G}$ & 1.73 & none & $\mathrm{F}$ \\
\hline 6,371 & $\mathrm{G}$ & $\mathrm{T}$ & 3.76 & non-coding & \multirow{8}{*}{$\mathrm{HN}$} \\
\hline 6,517 & A & $\mathrm{G}$ & 2.27 & $\mathrm{M} 34 \mathrm{~V}$ & \\
\hline 6,693 & $\mathrm{~T}$ & C & 5.55 & none & \\
\hline 7,404 & A & G & 2.86 & none & \\
\hline 7,649 & A & $\mathrm{C}$ & 1.12 & $\mathrm{H} 411 \mathrm{P}$ & \\
\hline 7,728 & $\mathrm{~T}$ & $\mathrm{G}$ & 11.21 & none & \\
\hline 8,175 & $\mathrm{G}$ & A & 2.39 & non-coding & \\
\hline 8,267 & A & $\mathrm{G}$ & 1.42 & non-coding & \\
\hline 9,274 & $\mathrm{~T}$ & $\mathrm{C}$ & 1.76 & none & \multirow{12}{*}{$\mathrm{L}$} \\
\hline 9,671 & C & A & 1.01 & $\mathrm{H} 429 \mathrm{~N}$ & \\
\hline 10,126 & $\mathrm{C}$ & $\mathrm{T}$ & 1.31 & none & \\
\hline 10,411 & $\mathrm{~T}$ & $\mathrm{C}$ & 1.81 & none & \\
\hline 11,059 & $\mathrm{G}$ & $\mathrm{A}$ & 2.1 & none & \\
\hline 13,417 & $\mathrm{C}$ & $\mathrm{T}$ & 2.16 & none & \\
\hline 13,463 & $\mathrm{C}$ & A & 1.26 & none & \\
\hline 13,690 & $\mathrm{~T}$ & $\mathrm{C}$ & 1.7 & none & \\
\hline 13,896 & A & $\mathrm{G}$ & 2.06 & K1837R & \\
\hline 14,173 & $\mathrm{C}$ & $\mathrm{T}$ & 1.71 & none & \\
\hline 14,929 & $\mathrm{~T}$ & $\mathrm{C}$ & 1.89 & none & \\
\hline 15,094 & $\mathrm{~T}$ & $\mathrm{~A}$ & 16.58 & non-coding & \\
\hline
\end{tabular}


One of them, present with frequency of $7.34 \%$, was a nonsynonymous mutation causing change of methionine to valine at position 1,674 of the L protein. Higher complexity was revealed in the viral population of the passaged isolate. Twenty-nine variant positions were identified in the coding regions and seven in the non-coding regions (Table 2). Ten mutations entailed change in amino acid sequence. In the NP protein, two variants with nonsynonymous mutations were detected. One of them was located at position 1,550 with frequency of $\sim 80 \%$, which was in agreement with the analysis of consensus sequences from Sanger sequencing. Three nonsynonymous mutations were detected in the $\mathrm{P}$ protein with variants at positions 2,154 and 2,407 present at a relatively high frequency. One and two low frequency amino acid substitutions were detected in the $\mathrm{M}$ and $\mathrm{HN}$ proteins, respectively. Two nonsynonymous mutations were also identified in the L gene (Table 2). None of the minority variants detected in the non-passaged isolate was maintained in the passaged isolate.

Histopathological findings. The intensity of lesions was the highest in pigeons, with chickens next and turkeys with the least intense changes. Generally, the observed histopathological lesions were mild but more pronounced in birds infected with the passaged PPMV-1.

Histopathological findings in pigeons. In the brain, multifocal mild perivascular mononuclear cell infiltration was noted on the $14^{\text {th }}$ dpi (Fig. 1A). At the same time focal perivascular infiltration of mononuclear cells affecting the meninges was observed. Multifocal gliosis with formation of nodules, mild neuronal degeneration, endothelial hypertrophy, oedema and congestion were also found. In the liver, multifocal, mild to moderate infiltration of mononuclear cells (mainly lymphocytes, plasma cells) and heterophils was observed in all groups of birds. Cellular infiltrates were found in portal triads, perivascular region, and in the subcapsular area. Heterophil infiltration was less prominent on the $14^{\text {th }}$ dpi than in the contact case (14 dpi_K). Although proliferation of Kupffer cells (hepatic macrophages) and hepatocyte lipid accumulation were observed in many sections, they were more prominent on the $10^{\text {th }}$ and $7^{\text {th }}$ dpi, respectively. Additionally, the presence of haemosiderin-laden macrophages was noted. Changes such as necrosis of hepatocytes of the periportal zone and biliary epithelial cell proliferation were present in one case (14 dpi). A predominant histological finding in the kidneys was diffuse marked interstitial nephritis (lymphoplasmacytic heterophilic), sometimes associated with tubular necrosis (10 dpi, 14 dpi, 14 dpi_K, Fig. 1 D). Occasionally, renal tubules were mildly dilated and filled with eosinophilic crystalline deposits. Additionally, the renal medulla was affected on the $14^{\text {th }}$ dpi and $14^{\text {th }}$ dpi_K. Moderate diffuse mononuclear cell infiltration and lymphoid aggregation (gut-associated lymphoid tissue (GALT) hyperplasia) were found in the duodenal mucosa on the $10^{\text {th }}$ and $14^{\text {th }}$ dpi. Marked multifocal lymphocytic pancreatitis was noted on the $14^{\text {th }}$ dpi when conspicuous to moderate multifocal necrosis of the pancreatic acinar cells was also observed as it also was on the $14^{\text {th }} \mathrm{dpi} \mathrm{K}$. In the lungs, the presence of lymphoid aggregates in the bronchial mucosa (bronchus-associated lymphoid tissue (BALT) hyperplasia) and within interstitial tissue was common on the $10^{\text {th }}$ and $14^{\text {th }}$ dpi (Fig. 1G). Surprisingly, a single granulomatous lesion with central necrosis surrounded by multinucleated giant cells was found in two cases (4 and $10 \mathrm{dpi}$ ).

Histopathological findings in chickens. The brain showed occasional scant perivascular mononuclear cell infiltration on the $4^{\text {th }}$ and $7^{\text {th }}$ dpi (Fig. 1 B). Some vessels indicated a slight endothelial hypertrophy. A mild increased glial hyperplasia and neuronal degeneration were frequently noted on the $7^{\text {th }}$ dpi. In the liver, multifocal moderate mononuclear cell infiltration, occasionally mixed with heterophils, and marked Kupffer cell hyperplasia was noted on the $7^{\text {th }}$ dpi. These findings were present on the $4^{\text {th }}$ dpi, but less intense than on the $7^{\text {th }}$ dpi. Lipid deposition in hepatocytes and periportal mild fibrosis were also observed. In the kidney on the $7^{\text {th }} \mathrm{dpi}$, there were multifocal mononuclear infiltrates associated with tubule necrosis (Fig. 1E). The kidney from both cases also revealed mild tubular degeneration and congestion. Diffuse mononuclear cell infiltration, mild GALT hyperplasia, and congestion were slightly more evident in the duodenal mucosa on the $7^{\text {th }}$ dpi. Enterocyte proliferation was higher on the $4^{\text {th }} \mathrm{dpi}$ than on the $7^{\text {th }} \mathrm{dpi}$. In the pancreas, there was a sparse mononuclear cell infiltrate, however, on the $7^{\text {th }}$ dpi more advanced lesions developed. An infiltration of mononuclear cells was followed by necrotic foci of the pancreatic acinar cells $(7 \mathrm{dpi}$ ). In the lungs, only focal lymphoid aggregates of the bronchial mucosa were observed on the $4^{\text {th }}$ and $7^{\text {th }}$ dpi (Fig. $1 \mathrm{H}$ ).

Histopathological findings in turkeys. In the brain, occasional neuronal degeneration, slight glial cell hyperplasia and congestion were observed. In the liver, the presence of inextensive focal mononuclear cell infiltration significantly distinguished the $7^{\text {th }}$ dpi samples from others. Marked diffuse hepatocellular lipid accumulation occurred on the $10^{\text {th }}$ dpi. Scant interstitial focal nephritis was observed on dpi 4 and 7, with mild focal haemorrhages on the $4^{\text {th }}$ dpi (Fig. 1F). The duodenal mucosa showed mild diffuse mononuclear cell infiltration, occasionally with scant focal GALT hyperplasia (10 dpi). In the kidney, scant focal interstitial nephritis was observed on dpi 4 and 7 , with mild focal haemorrhages on dpi 4 . The pancreas revealed small foci of mononuclear cells (10 dpi) and vacuolation of single acinar cells. In the lungs and brain, there were no differences between cases. In the lungs, slight focal BALT hyperplasia and mild marginal emphysema were noted (Fig. 1H). 

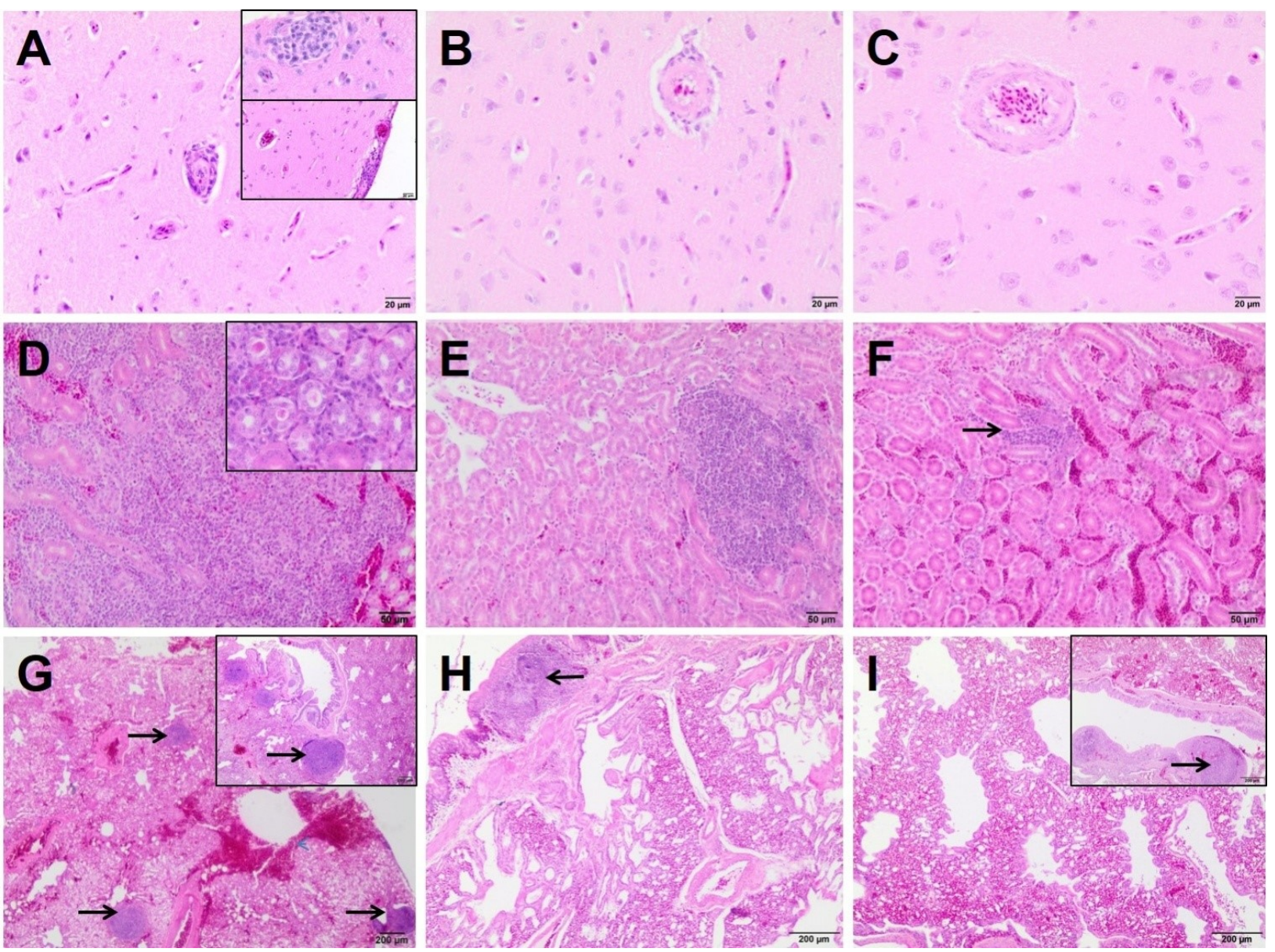

Fig. 1. Representative images of the brain (A-C), kidney (D-F), and lung (G-I) from pigeons (A, D, G), chickens (B, E, H), and turkeys (C, F, I) comparing the severity of diagnosed lesions between groups

Brain: mononuclear inflammatory infiltrates in perivascular spaces and gliosis were more marked in pigeons (A) than chickens (B). Turkeys demonstrated no encephalitis (C). An insert in the right corner of Fig. 1A shows a glial nodule, and focal lymphoplasmacytic meningitis

Kidney: in pigeons there were severe diffuse interstitial nephritis composed primarily of mononuclear cells and a smaller number of heterophils, with tubular necrosis (D). An insert image in the upper right corner of Fig. 1D shows eosinophilic crystalline deposits filling tubular lumens. In chickens multifocal infiltration of mononuclear cells and focal tubular degeneration or necrosis (E) were seen, whereas in turkeys scanty focal interstitial nephritis (arrow) and haemorrhages were shown (F)

Lung: multifocal lymphoid aggregates (arrows) scattered throughout the interstitial pulmonary tissue in pigeons (G); BALT hyperplasia was observed among all birds (arrows, insert images $1 \mathrm{G}$ and $1 \mathrm{I}$; and Fig.1H). However, in chickens and turkeys this finding was the only one that was a more notable pulmonary change

HE. Scale bar indicates $20 \mu \mathrm{m}(\mathrm{A}-\mathrm{C}), 50 \mu \mathrm{m}(\mathrm{D}-\mathrm{F}), 200 \mu \mathrm{m}(\mathrm{G}-\mathrm{I})$

\section{Discussion}

In the previous study (31), we investigated the clinical course, virus distribution, replication, and transmission of PPMV-1 in various species of birds and found that only pigeons succumbed to the infection, while chickens, turkeys, geese, and quail remained healthy. The virus showed different levels of replication and shedding. It was shown that PPMV-1 requires a series of passages in chickens in order to regain adaptation and pathogenic potential in Galliformes (11), so to increase the level of PPMV-1 adaptation to gallinaceous poultry, serial passages of the native PPMV-1 strain in chickens were performed. Despite a slight increase in virulence (as measured by the intracerebral pathogenicity index value, ICPI) no noticeable difference in terms of clinical manifestation between non-passaged and passaged PPMV-1 was observed.

The present study is a follow-up investigation in which we analysed the distribution of viral quasispecies in the virus stock obtained from the original PPMV-1 isolate and the same strain passaged several times in SPF chickens. Additionally, it describes microscopic lesions induced by both strains in pigeons and two representatives of gallinaceous birds: chickens and turkeys.

The Sanger sequencing of 332/05/0 and 332/05/6 revealed one nonsynonymous mutation $(\mathrm{H} 477 \mathrm{~N})$ in the consensus sequence of NP. However, previous studies showed that the composition of NDV viral quasispecies is an important factor contributing to the virulence (5, $16,23)$, therefore we decided to deepen the analysis to the level of viral subpopulations of the non-passaged 
and passaged virus stocks. The high-throughput sequence analysis of the quasispecies populations in the non-passaged PPMV-1 revealed only one minor variant with nonsynonymous mutation. In contrast, in the passaged PPMV-1 ten nonsynonymous mutations were identified with only one dominant substitution (H477N) in the NP protein $(\sim 80 \%$ frequency $)$, which corroborated the results of Sanger sequencing. There was no variation at this position in the non-passaged isolate, which suggests that this mutation emerged during passages. Two nonsynonymous minority variants in the $\mathrm{P}$ protein occurred with a noticeable frequency of $\sim 17 \%$ to $\sim 20 \%$. The frequency of the remaining substitutions was very low (approx. 1\%$2 \%$ ). Therefore, the quasispecies distribution in passaged PPMV-1 was slightly but unequivocally different (both genetically and phenotypically), from the original virus population in non-passaged PPMV-1.

None of the low-frequency variants present in the non-passaged virus stock was detected in the passaged virus, and vice versa. It suggests that the selection pressure of the new host (chicken) sparked phenotypic alterations in the tested PPMV-1 and the emergence of a distinct mutant spectrum in the passaged isolate can explain the observed changes in ICPI values obtained in the previous paper (31). The observed substitutions are located in the $\mathrm{NP} / \mathrm{P} / \mathrm{L}$ proteins that together form the replication complex of the virus. Previous experiments showed an increase in the virulence of PPMV-1 as a result of passages in chickens. No mutations in the F protein were observed in that study, but augmented virulence was caused by mutations in the polymerase complex proteins (11). The presence of a polybasic cleavage site of the $\mathrm{F}$ protein does not always correlate with the pathogenicity (10), which was also demonstrated for avian paramyxovirus 2 (APMV-2) (30). The observed changes at the molecular level can explain differences in the intensity of histopathological lesions that were more pronounced in tissues collected from birds infected with the passaged PPMV-1.

The NP encapsidates the viral RNA, and thus it participates in the regulation of replication, transcription and virus assembly. The mutation $\mathrm{H} 477 \mathrm{~N}$ in the NP is located in the C-terminal region, within a domain that probably has high functional and structural significance (residues 442-489) (22), including interaction with the $\mathrm{P}$ protein and RNA synthesis $(17,33)$, therefore it might affect the efficiency of virus replication. A previous study showed that mutation NP-E402A caused enhanced synthesis of viral RNA in a cell culture at the beginning of infection but that it decreased later on which resulted in reduced replication of the virus from 36 hours post infection compared to the wild-type strain possessing NP-E402 (33). A higher level of viral RNA entailed increased efficiency of virus production leading to faster death of infected cells, which restrained the virus replication at the later stages of infection. The mutated virus also showed higher virulence for 1-day-old chicks as evidenced by a higher value of ICPI when lower virus doses were used (33). Similarly, mutation H477N might also contribute to an increased ICPI value of the passaged PPMV-1 and enhance the virus replication in the tested species. This might also be the reason for more pronounced lesions in organs from birds infected with the passaged virus. The correlation between the virus load, innate immune response, and intensity of histopathological lesions has been observed in another study (13). Nevertheless, the role of NP-H477N mutation in the alteration of virus virulence and its effect on the microscopic lesions needs further investigation. As regards the examined species, the lesions were most prominent in pigeons followed by chickens and turkeys. The striking difference in the extent and intensity of lesions between pigeons and Galliformes is explained by the existence of hostspecific adaptive features which have been only partially identified at molecular level (11).

PPMV-1 is highly adapted to pigeons and lesions caused by the virus in tissues of its natural host are systemic and occasionally quite extensive. Some of the lesions found in our study were consistent with those described in previous reports, for example: perivascular lymphocytic cuffings and gliosis in the brain, nephritis and tubular necrosis in the kidneys, lymphocytic pancreatitis, and pulmonary congestion $(6,15,27)$. It was shown previously that PPMV-1 is neuro- and nephrotropic $(14,21,28)$ and our findings corroborate these observations.

Descriptions of microscopic lesions caused by PPMV-1 in chickens are scarce. The microscopic lesions found in our study were mild but involved multiple organs. Kommers et al. (19) reported that the most remarkable findings in chickens had been observed in the brain and included mononuclear inflammatory infiltrations, perivascular cuffs, endothelial cell hyperplasia, chromatolysis in the cerebral neurons, areas of gliosis, Purkinje cell necrosis, and vacuolisation in the cerebellar white matter. Although not all birds with lesions in the brain suffered from neurological conditions, the authors concluded that PPMV-1 is neurotropic in chickens. In our study, neurological signs were not observed, and lesions detected in the brain were mild and scant. This discrepancy can be explained by the age differences of birds used in the studies and/or variations in the individual pathogenic properties of the PPMV-1 strains used for inoculation in various experiments. To the best of our knowledge, histologic lesions induced by PPMV-1 in turkeys have not been described so far. In the present study, we found mild to moderate inflammatory lesions (focal or diffuse infiltration of cells) in the liver, kidneys, duodenum and pancreas as well as slight glial hyperplasia and neuronal degeneration. The combined clinical and pathological data obtained for chickens and turkeys clearly indicate that passaging of pigeon-derived PPMV-1 isolates in chickens does not always occasion a significant 
alteration of the pathogenic properties following inoculation by natural routes (respiratory/digestive), although, as mentioned above, a qualitative assessment of histological findings indicated more pronounced microscopic lesions in tissues collected from birds infected with the passaged PPMV-1. The results obtained in our study warrant further investigations on the role of specific mutations produced in the polymerase complex of the virus as a result of passaging in gallinaceous birds, especially in the context of tissue tropism and intensity of lesions.

Conflict of Interests Statement: The authors declare that there is no conflict of interests regarding the publication of this article.

Financial Disclosure Statement: This work was supported by the Ministry of Science and Higher Education in Poland (Grant No. N N308 564939).

Animal Rights Statement: The experiments were approved by the II Local Ethics Committee of Animal Experimentation in Lublin.

\section{References}

1. Alexander D.J.: The epidemiology and control of avian influenza and Newcastle disease. J Comp Pathol 1995, 112, 105-126.

2. Alexander D.J.: Newcastle disease in the European Union 2000 to 2009. Avian Pathol 2011, 40, 547-558.

3. Alexander D.J., Parsons G., Marshall R.: Infection of fowls with Newcastle-disease virus by food contaminated with pigeon feces. Vet Rec 1984, 115, 601-602.

4. Amarasinghe G.K., Aréchiga Ceballos N.G., Banyard A.C., Basler C.F., Bavari S., Bennett A.J., Blasdell K.R., Briese T., Bukreyev A., Caì Y., Calisher C.H., Campos Lawson C., Chandran K., Chapman C.A., Chiu C.Y., Choi K.S., Collins P.L., Dietzgen R.G., Dolja V.V., Dolnik O., Domier L.L., Dürrwald R., Dye J.M., Easton A.J., Ebihara H., Echevarría J.E., Fooks A.R., Formenty P.B.H., Fouchier R.A.M., Freuling C.M., Ghedin E., Goldberg T.L., Hewson R., Horie M., Hyndman T.H., Jiāng D., Kityo R., Kobinger G.P., Kondō H., Koonin E.V., Krupovic M., Kurath G., Lamb R.A., Lee B., Leroy E.M., Maes P., Maisner A., Marston D.A., Mor S.K., Müller T., Mühlberger E., Ramírez V.M.N., Netesov S.V., Ng T.F.F., Nowotny N., Palacios G., Patterson J.L., Pawęska J.T., Payne S.L., Prieto K., Rima B.K., Rota P., Rubbenstroth D., Schwemmle M., Siddell S., Smither S.J., Song Q., Song T., Stenglein M.D., Stone D.M., Takada A., Tesh R.B., Thomazelli L.M., Tomonaga K., Tordo N., Towner J.S., Vasilakis N., Vázquez-Morón S., Verdugo C., Volchkov V.E., Wahl V., Walker P.J., Wang D., Wang L.F., Wellehan J.F.X., Wiley M.R., Whitfield A.E., Wolf Y.I., Yè G., Zhāng Y.Z., Kuhn J.H.: Taxonomy of the order Mononegavirales: update 2017. Arch Virol 2017, 162, 2493-2504.

5. Barbezange C., Jestin V.: Quasispecies nature of an unusual avian paramyxovirus type-1 isolated from pigeons. Virus Genes 2005, 30, 363-370.

6. Barton J.T., Bickford A.A., Cooper G.L., Charlton B.R., Cardona C.: Avian paramyxovirus type 1 infections in racing pigeons in California, I: clinical signs, pathology, and serology. Avian Dis 1992, 36, 463-468.

7. Bolger A.M., Lohse M., Usadel B.: Trimmomatic: a flexible trimmer for Illumina sequence data. Bioinformatics 2014, 30, 2114-2120.
8. CEC 1992. Council Directive 92/66/EEC of 14 July 1992 introducing Community measures for the control of Newcastle disease. Off J Eur Commun L260, pp. 1-20.

9. Dimitrov K.M., Ramey A.M., Qiu X., Bahl J., Afonso C.L.: Temporal, geographic, and host distribution of avian paramyxovirus 1 (Newcastle disease virus). Infect Genet Evol 2016, 39, 22-34

10. Dortmans J.C., Rottier P.J., Koch G., Peeters B.P.: The viral replication complex is associated with the virulence of Newcastle disease virus. J Virol 2010, 84, 10113-10120.

11. Dortmans, J.C., Rottier P J., Koch G., Peeters B.P.: Passaging of a Newcastle disease virus pigeon variant in chickens results in selection of viruses with mutations in the polymerase complex enhancing virus replication and virulence. J Gen Virol 2011, 92, 336-345.

12. Dortmans J.C., Koch G., Rottier P.J., Peeters B.P.: Virulence of Newcastle disease virus: what is known so far? Vet Res 2011, 42, 122 .

13. Ecco R., Brown C., Susta L., Cagle C., Cornax I., Pantin-Jackwood M., Miller P.J., Afonso C.L.: In vivo transcriptional cytokine responses and association with clinical and pathological outcomes in chickens infected with different Newcastle disease virus isolates using formalin-fixed paraffinembedded samples. Vet Immunol Immunopathol 2011, 141, 221-229.

14. Guo H., Liu X., Xu Y., Han Z., Shao Y., Kong X., Liu S.: A comparative study of pigeons and chickens experimentally infected with PPMV-1 to determine antigenic relationships between PPMV-1 and NDV strains. Vet Microbiol 2014, 168, 88-97.

15. Isidoro-Ayza M., Afonso C.L., Stanton J.B., Knowles S., Ip H.S., White C.L., Fenton H., Ruder M.G., Dolinski A.C., Lankton J.: Natural infections with pigeon Paramyxovirus serotype 1: Pathologic changes in Eurasian collared-doves (Streptopelia decaocto) and rock pigeons (Columba livia) in the United States. Vet Pathol 2017, 54, 695-703.

16. Kattenbelt J.A., Stevens M.P., Selleck P.W., Gould A.R.: Analysis of Newcastle disease virus quasispecies and factors affecting the emergence of virulent virus. Arch Virol 2010, 155, 1607-1615.

17. Kho C.L., Tan W.S., Tey B.T., Yusoff K.: Regions on nucleocapsid protein of Newcastle disease virus that interact with its phosphoprotein. Arch Virol 2004, 149, 997-1005.

18. Koboldt D.C., Larson D.E., Wilson R.K.: Using VarScan 2 for germline variant calling and somatic mutation detection. Curr Protoc Bioinform 2013, 44, 15.4.1-15.4.17.

19. Kommers G.D., King D.J., Seal B.S., Carmichael K.P., Brown C.C.: Pathogenesis of six pigeon-origin isolates of Newcastle disease virus for domestic chickens. Vet Pathol 2002, 39, 353-362.

20. Li H., Durbin R.: Fast and accurate short read alignment with Burrows-Wheeler transform. Bioinformatics 2009, 25, 1754-1760.

21. Marlier D., Vindevogel H.: Viral infections in pigeons. Vet $\mathrm{J}$ 2006, 172, 40-51.

22. Mebatsion T., Koolen M.J., de Vaan L.T., de Haas N., Braber M., Römer-Oberdörfer A., van den Elzen P., van der Marel P.: Newcastle disease virus (NDV) marker vaccine: an immunodominant epitope on the nucleoprotein gene of NDV can be deleted or replaced by a foreign epitope. J Virol 2002, 76, 10138-10146.

23. Meng C., Qiu X., Yu S., Li C., Sun Y., Chen Z., Liu K., Zhang X., Tan L., Song C., Liu G., Ding C.: Evolution of Newcastle disease virus quasispecies diversity and enhanced virulence after passage through chicken air sacs. J Virol 2015, 90, 2052-2063.

24. Meulemans G., van den Berg T.P., Decaesstecker M., Boschmans M.: Evolution of pigeon Newcastle disease virus strains. Avian Pathol 2002, 31, 515-519. 
25. Milne I., Bayer M., Cardle L., Shaw P., Stephen G., Wright F., Marshall D.: Tablet - next generation sequence assembly visualization. Bioinformatics 2010, 26, 401-402.

26. Paldurai A., Kim S.H., Nayak B., Xiao S., Shive H., Collins P.L., Samal S.K.: Evaluation of the contributions of individual viral genes to Newcastle disease virus virulence and pathogenesis. J Virol 2014, 88, 8579-8596.

27. Pearson J.E., Senne D.A., Alexander D.J., Taylor W.D., Peterson L.A., Russell P.H.: Characterization of Newcastle disease virus (avian paramyxovirus-1) isolated from pigeons. Avian Dis 1987, 31, 105-111.

28. Pestka D., Stenzel T., Koncicki A.: Occurrence, characteristics, and control of pigeon paramyxovirus type 1 in pigeon. Pol J Vet Sci 2014, 17, 379-384.

29. Steward M., Vipond I.B., Millar N.S., Emmerson P.T.: RNA editing in Newcastle disease virus. J Gen Virol 1993, 74, 2539-2547.
30. Subbiah M., Khattar S.K., Collins P.L., Samal S.K.: Mutations in the fusion protein cleavage site of avian paramyxovirus serotype 2 increase cleavability and syncytium formation but do not increase viral virulence in chickens. J Virol 2011, 85, 5394-53405.

31. Śmietanka K., Olszewska M., Domańska-Blicharz K., Bocian L., Minta Z.: Experimental infection of different species of birds with pigeon paramyxovirus type 1 virus-evaluation of clinical outcomes, viral shedding, and distribution in tissues. Avian Dis 2014, 58, 523-530.

32. Tamura K., Stecher G., Peterson D., Filipski A., Kumar S.: MEGA6: molecular evolutionary genetics analysis version 6.0. Mol Biol Evol 2013, 30, 2725-2729.

33. Yu X., Cheng J., He Z., Li C., Song Y., Xue J., Yang H., Zhang R., Zhang G.: The glutamic residue at position 402 in the C-terminus of Newcastle disease virus nucleoprotein is critical for the virus. Sci Rep 2017, 7, 17471. 